\title{
A competitive analysis of port of Hong Kong: from external to internal
}

\author{
Zihua Liu', Dong Yang ${ }^{2^{*}}$ and Y. N. Eppie $\mathrm{Ng}^{2}$
}

\author{
* Correspondence: dong.yang@ \\ polyu.edu.hk \\ ${ }^{2}$ Shipping Research Centre, The \\ Hong Kong Polytechnic University, \\ Hong Kong SAR, China \\ Full list of author information is \\ available at the end of the article
}

\begin{abstract}
This paper aims to analyse the competitive equilibrium of Hong Kong international port after the cooperation among terminal operators. To achieve our research objective, a comprehensive analysis framework is proposed. We assume that the port services provided by Shenzhen and Hong Kong have heterogeneity, thus apply Cournot price competition model to understand the external competition. We find that the heterogeneity level can affect the demand of Hong Kong international port. For different heterogeneity levels, different competitive equilibriums among terminal operators of Hong Kong are discussed. We further apply Edgeworth model and Stackelberg Leadership Model to describe the internal competition of Hong Kong international port. Based on analysis, some recommendations are provided to the terminal operators of Hong Kong.

Keywords: Terminal/port competition, Service heterogeneity, Cournot price competition, Edgeworth model, Stackelberg leadership model
\end{abstract}

\section{Introduction}

With the current dynamic business environment, port and container terminal operators in the same region are facing keen competition from each other (Kaselimi et al. 2011). In recent years, liner shipping companies restructure and reform their shipping alliances, which significantly improves their bargaining power towards port and container terminal operators and port competition arises. In response to such competition, port and container terminal operators actively review and evaluate possible solutions. Port and container terminal operators are resolved to cooperate in order to improve service efficiency facing the inter-port competition posed by external pressure. A recent example is the partnership between the seaports of Seattle and Tacoma. The two ports formed the Northwest Seaport Alliance approved by the U.S. Federal Maritime Commission in July 2015 with an aim to enable "joint marketing, planning and infrastructure development" (Mongelluzzo 2015). On the other hand, container terminal operators in the same port also cooperate to tackle such inter-port competition. Facing the rapid development of the Port of Shenzhen, container terminal operators in the Port of Hong Kong collaborated in 2016. With lower cost and increasing efficiency, the Port of Shenzhen is one of the key competitors facing the Port of Hong Kong. The

(c) The Author(s). 2020 Open Access This article is licensed under a Creative Commons Attribution 4.0 International License, which permits use, sharing, adaptation, distribution and reproduction in any medium or format, as long as you give appropriate credit to the original author(s) and the source, provide a link to the Creative Commons licence, and indicate if changes were made. The images or other third party material in this article are included in the article's Creative Commons licence, unless indicated otherwise in a credit line to the material. If material is not included in the article's Creative Commons licence and your intended use is not permitted by statutory regulation or exceeds the permitted use, you will need to obtain permission directly from the copyright holder. To view a copy of this licence, visit http://creativecommons.org/licenses/by/4.0/. 
throughput of the Port of Shenzhen has exceeded the Port of Hong Kong since 2013, and the container terminal operators in Hong Kong have been facing the over-capacity problem (Hong Kong Marine Department 2018).

Formerly there were five container terminal operators operating independently in the Port of Hong Kong before the collaboration in December 2016, namely Modern Terminals Limited (MTL), Goodman DP World Hong Kong Limited (DPI), Hong Kong International Terminals Limited (HIT), COSCO-HIT Terminals (Hong Kong) Limited (CHT) and Asia Container Terminals Limited (ACT), as shown in Fig. 1.

On 19th December 2016, Hutchison Ports HIT (2016), HIT, COSCO-HIT Terminals (Hong Kong) Limited (CHT) and Asia Container Terminals Limited (ACT) announced the news of collaboration with an aim to achieve effective and efficient management and operations. A specific management team has been appointed for the container terminal operations. In contrast, MTL and DPI remained independent operations. Table 1 shows the change of container terminal operators before and after the collaboration.

With the new collaboration, container terminal operations have transformed. Previously, cargoes belong to two different liner shipping companies on one pooling ship can only be loaded in one terminal in the Port of Hong Kong. If one liner shipping company has no contract with this terminal, its cargoes need to be delivered to the contractual terminal for transshipment, which leads to additional costs. Ma et al. (2019) point out that for Hong Kong Port (HKP), a port with five operators, interterminal transfer (ITT) of containers becomes a major problem and burden. After conducting numerical experiments based on real data collected from HKP, they find that sharing economy concept works well to reduce operating cost, while improving the service quality without sacrificing benefits of individual operators. In fact, the HIT/ACT/ $\mathrm{CHT}$ collaboration enables effective and efficient facilities management and resources allocation, which eventually lower the operation costs. Hutchison Port Holdings Trust

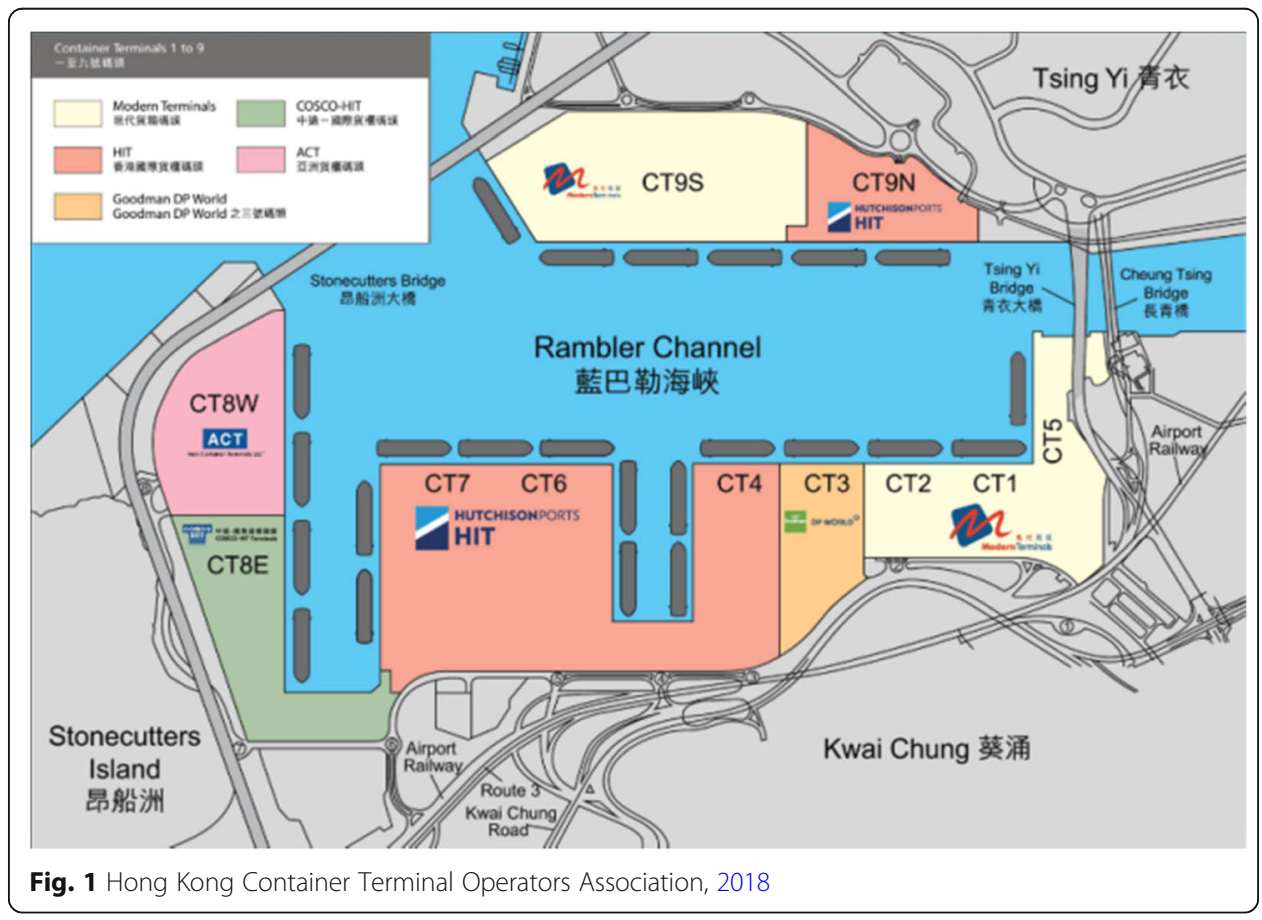


Table 1 Hong Kong Container Terminal Operators Association, 2018, before \& after collaboration

\begin{tabular}{llllll}
\hline Operator & MTL & DPI & CHT & ACT & HIT \\
\hline Before & & & & & \\
Terminal & $\mathrm{T} 1,2,5,9$ & $\mathrm{~T} 3$ & T8 east & T8 west & $\mathrm{T} 4,6,7,9$ \\
Berth No. & 7 & 1 & 2 & 2 & 12 \\
After & & & & \\
Terminal & $\mathrm{T} 1,2,5,9$ & $\mathrm{~T} 3$ & $\mathrm{~T} 4,6,7,8,9$ North & \\
Berth No. & 7 & 1 & 16 & & \\
\hline
\end{tabular}

Note: MTL-Modern Terminal, DPI-DP World, CHT-COSCO/HIT Terminals, ACT-Aqaba Container Terminal, HIT-Hong Kong International Terminals

(2017) demonstrates that the staff cost was decreased by $4.1 \%$ or HK\$9.2 million lowered than the previous year. Hutchison Port Holdings Trust (2017) also points out that the savings in operation costs from efficient allocation of resources after the commencement of the collaboration offset the increase in the cost of services, which was $2.4 \%$ or HK\$25.5 million compared with the previous year.

The collaboration among container terminal operators as described has triggered a chain reaction on the status quo of the Port of Hong Kong (HKP): Firstly, the internal competition among different container terminals in Hong Kong changes. Secondly, HKP as a whole will also compete with its external competitor - Shenzhen port (SZP). HKP and SZP are two major ports not only in South China but also in the world, as shown in Fig. 2. SZP ranked No.4 in 2018 with container throughput of 25,740,000 TEUs while HKP ranked No.7 with container throughput of 19,590,000 TEUs. With the collaboration of container terminal operators inside Hong Kong, HKP and SZP compete in different ways now. By applying economic models, this study aims to understand the competitive equilibrium between HKP and SZP, as well as the competitive equilibrium among container terminal operators in HKP.

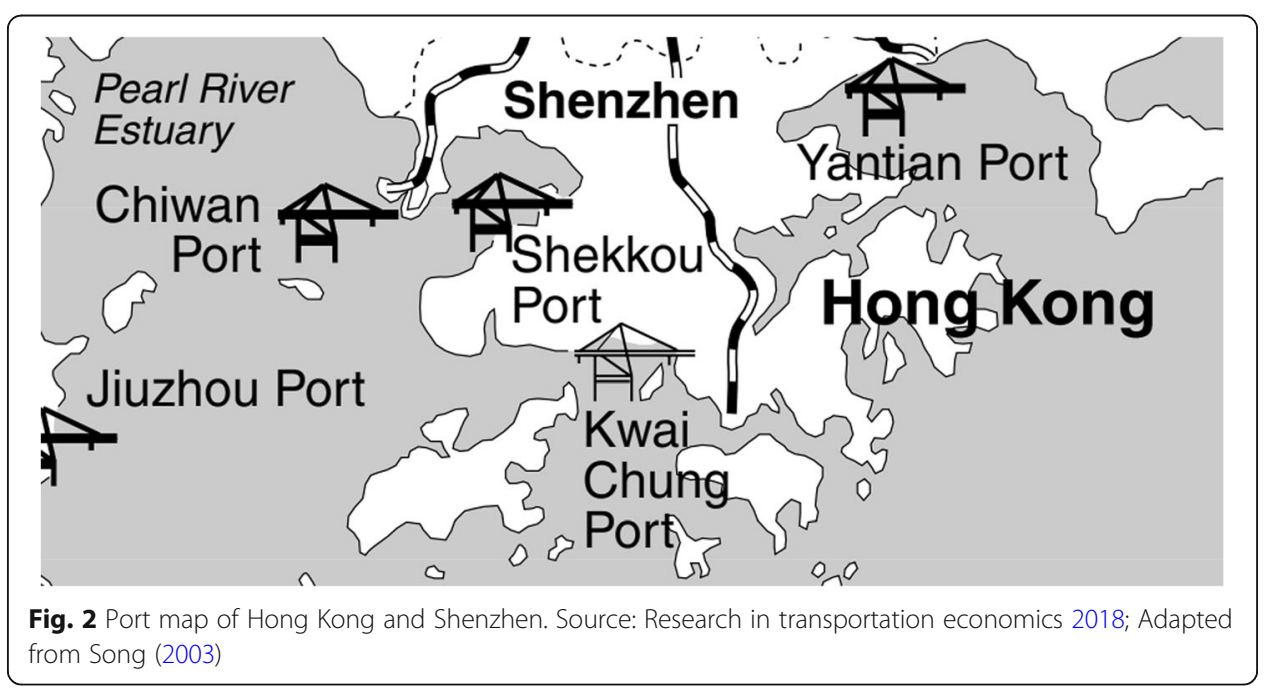




\section{Literature review}

There is a significant number of studies in the theme of port competition. Scholars adopted different approaches to study this topic, such as mathematical approach, economic approach, and strategic approach. Veldman and Bückmann (2003) analyse the container port competition in western European hubs by applying the logit model of the choice of shipping routes to derive the demand function. Cullinane et al. (2005) study the inter-port competition of Shanghai and Ningbo by taking the generalised costs of carriers into consideration. Song (2002) examines the situations faced by the container terminals in South China and proposes possible development strategies under three scenarios of steady growth, high growth, and extra high growth.

In general, there are two types of port competition, namely inter-port competition and intra-port competition. Inter-port competition refers to the competition between two neighboring ports or ports in the same region. The application of game theory is widely adopted to analyse both types of competition. Anderson et al. (2008) adopt a game theoretic approach to describe the inter-port competition between container port hubs, Busan and Shanghai. Each port must decide whether to make an investment in the development of infrastructure that will be more appealing to certain types of cargoes. A pricing game is applied in terms of the observed price or forecasting price. A two-stage game is developed by De Borger et al. (2008) to examine the interaction between capacity decisions and prices of two ports in congested hinterlands. Ishii et al. (2013) develop a game theoretical model to explain inter-port competition under demand uncertainty and derive the unique equilibrium. Do et al. (2015) study the interport competition between HKP and SZP. An uncertain payoff two-player game model is proposed and solved with uncertain theory and Nash equilibrium strategy. The pure strategy set of each player (HKP and SZP) includes two strategies of not invest and invest. Park et al. (2010) apply two game models, including Cournot model to analyse the competition and cooperation between ports. The ports in an oligopoly market are suggested to join hand to improve their profits. Lee et al. (2017) evaluate the port strategy in view of all trading countries and compare the equilibriums under Bertrand and Cournot competition. They conclude that exporting country prefers Cournot competition and importing country prefers Bertrand competition. Davidson and Deneckere (1986) analyse the nature of Cournot equilibrium in a special market, where firms choose the scale of operation before they make pricing decisions. They find that in such market, the equilibrium will be more competitive than that in Cournot model and also summarise that the mixed strategies applied by firms cause their asymmetric sizes and price dispersion.

Intra-port competition is defined as the competition among container terminal operators in the same port. Saeed and Larsen (2010) describe the relationship among the terminals under Karachi port within the framework of non-cooperative and cooperative game. The game is divided into two-stages. In the first stage, three terminals at Karachi port decide whether to operate independently or to join the coalition. In the second stage, terminals who have decided to become a part of the coalition play a noncooperative game against non-members. Four possible combinations of coalition are presented. Each of them is formulated in game structure and solved numerically in terms of Bertrand model. Kaselimi et al. (2011) examine the competition among multiuser terminals in one port and between ports. The studied two ports are assumed to be 
identical in all respects, except for location and number of terminal operators. Cournot model is applied to analyse the competition between multi-user terminals and Hotelling model is used to study the competition between two ports based on their respective locations. A linear market area of unit length is assumed, with identical consumers evenly spread over this interval.

In reality, ports are facing both inter-port competition and intra-port competition simultaneously. Luo et al. (2012) develop a two-stage duopoly model incorporating two heterogeneous ports' pricing and capacity decisions to study the competition between HKP and SZP. The necessary conditions to increase profit are to expand capacity and to invalidate the preemptive pricing of dominant player. From the analysis, the rapid development of Shenzhen port will change the market power from monopoly to duopoly. Ivaldi and Vibes (2005) propose a simulation model to analyse the intermodal and intramodal competition in transport industry within a differentiated product framework under oligopoly structure. The authors conclude that all the potential travelers, companies and modes should be considered when predicting the market equilibrium. This conclusion triggers the point of heterogeneity in our paper because the competitive relationship between different modes is similar to that in the case of HKP and SZP.

We build upon the previous literature in the four following aspects: (i). we consider the internal competition (intra-port competition) and external competition (inter-port competition) with game theory simultaneously. In particular, we link the internal and external competition and discuss the interaction between them; (ii). we assume that there is heterogeneity between the services provided by SZP and HKP. The equilibrium model for both internal and external competition is established based on the heterogeneity between HKP and SZP; (iii). the selection procedure of the strategic variable for the intra-port competition of HKP is performed with the consideration of heterogeneity, which is the key factor significantly affecting the result of external competition; (iv). we propose some insights for container terminal operators in HKP to maintain and improve their current positions.

\section{Methodology}

In this section, we will introduce the models applied to solve the proposed research questions. Different economic models will be proposed to analyse the competitive equilibrium between HKP and SZP, and the competitive equilibrium among container terminal operators in HKP. Both HKP and SZP have their own advantages in competition. The operation cost of SZP is lower due to cheaper labour and land cost, while HKP enjoys a high degree of free trade, and highly efficient customs clearance and terminal operations. In another word, HKP provides more efficient port services with higher price while SZP provides relatively less efficient port services with lower price. Luo et al. (2012) identify the heterogeneity in the case of HKP and SZP mainly as the difference in price sensitivities, operation efficiency, and costs. Therefore, the port services offered by HKP and SZP can be regarded as heterogeneous products. Cournot model is frequently applied to study the competitive equilibrium of two competitive players in terms of throughput. However, it assumes that two players provide homogeneous products/services. Price competition is the usual strategy adopted by differentiated oligopolies, because consumers will choose products with better quality under the same price. In order to attract consumers, the oligopoly who produces lower-quality products will 
set a lower price. In our case, since the services provided by HKP and SZP are considered as heterogeneous products, Cournot model will not be the suitable model for analysis. Alternatively, the Cournot price competition model (Cournot 1838) will be applied to explore the competitive equilibrium between HKP and SZP.

We assume that the container terminal operators in HKP provide homogeneous services, at which the heterogeneity between HKP and SZP determines the internal competition model of HKP. Given a fixed port fee, the improvement of efficiency in the port services of SZP indicates the decreasing heterogeneity between HKP and SZP thus the comparative advantages of HKP will be weakened. With such, SZP is preferable to consumers and the demand for HKP will decrease. With the decrease in total throughput level, price competition will not be an optimal option to the container terminal operators of HKP. The reasons are provided as follows:

The decreasing heterogeneity between HKP and SZP caused by the efficiency improvement of SZP will lead to an increase in the price elasticity of both ports and the marginal cost of HKP. As a result, if Hong Kong terminal operators compete by price, there will be two possible scenarios: i). if they choose to increase the price, when the price is inelastic, setting a higher price will lead to a revenue growth. However, the price elasticity is increasing with the decreasing heterogeneity between HKP and SZP. In long term, the revenue will finally decrease once the price becomes elastic; ii). if they choose to reduce the price, considering the relatively high cost of HKP and the increasing marginal cost, the available range for price reduction is minimal, otherwise a loss will arise. In the long term, with the continuously decreasing heterogeneity between HKP and SZP, price competition is not a sustainable strategy for Hong Kong terminal operators.

Thus, competition in terms of capacity will be adopted. Four models have been considered as candidates: First of all, Cournot model is eliminated because of its assumption that firms produce a certain amount of goods simultaneously and independently, which does not match the case of HKP; Chamberlin's model, as the updated version of Cournot model, is not suitable because its conclusion is drawn based on assuming a stable equilibrium which can be reached with monopoly price; Since the terminals under HKP indeed produce homogeneous products, Sweezy-kinked demand curve model is deleted. Considering the large difference in the capacity of the HIT/ACT/ CHT collaboration and MTL (16:7), Stackelberg Leadership model is then the most suitable model to analyse the intra-port competition.

If the port fees of both HKP and SZP are fixed and the level of heterogeneity of these two ports becomes high, the total throughput level of HKP will increase. Since HKP faces a problem of capacity limitation, Bertrand model is not applicable considering its assumption of unlimited capacity. Apart from this, Hotelling model and Cournot price competition model have also been considered. However, these two are designed for heterogeneous competition. Finally, Edgeworth model, as the updated version of Bertrand model, taking account of limited capacity of firms (Edgeworth 1897), is selected to describe the internal competition. Therefore, under Edgeworth model, the HIT/ ACT/CHT collaboration will then compete in price with MTL.

Finally, we will connect these models to explore: (i). the overall competitive equilibrium for not only container terminal operators (intra-port) but also HKP and SZP (inter-port); (ii). the impact of heterogeneity level on the equilibrium; (iii). the strategies for container terminal operators of HKP to maintain and improve their positions. 


\section{Ports and container terminals competition analysis}

After the commencement of the HIT/ACT/CHT collaboration in HKP, they run 16 terminals out of 24, whereas MTL and DPI run 7 and 1 terminals respectively. The resource of DPI is very limited thus it will be ignored in our analysis, and a two-player game is considered for intra-port competition in HKP. The notations of this paper are as follows:

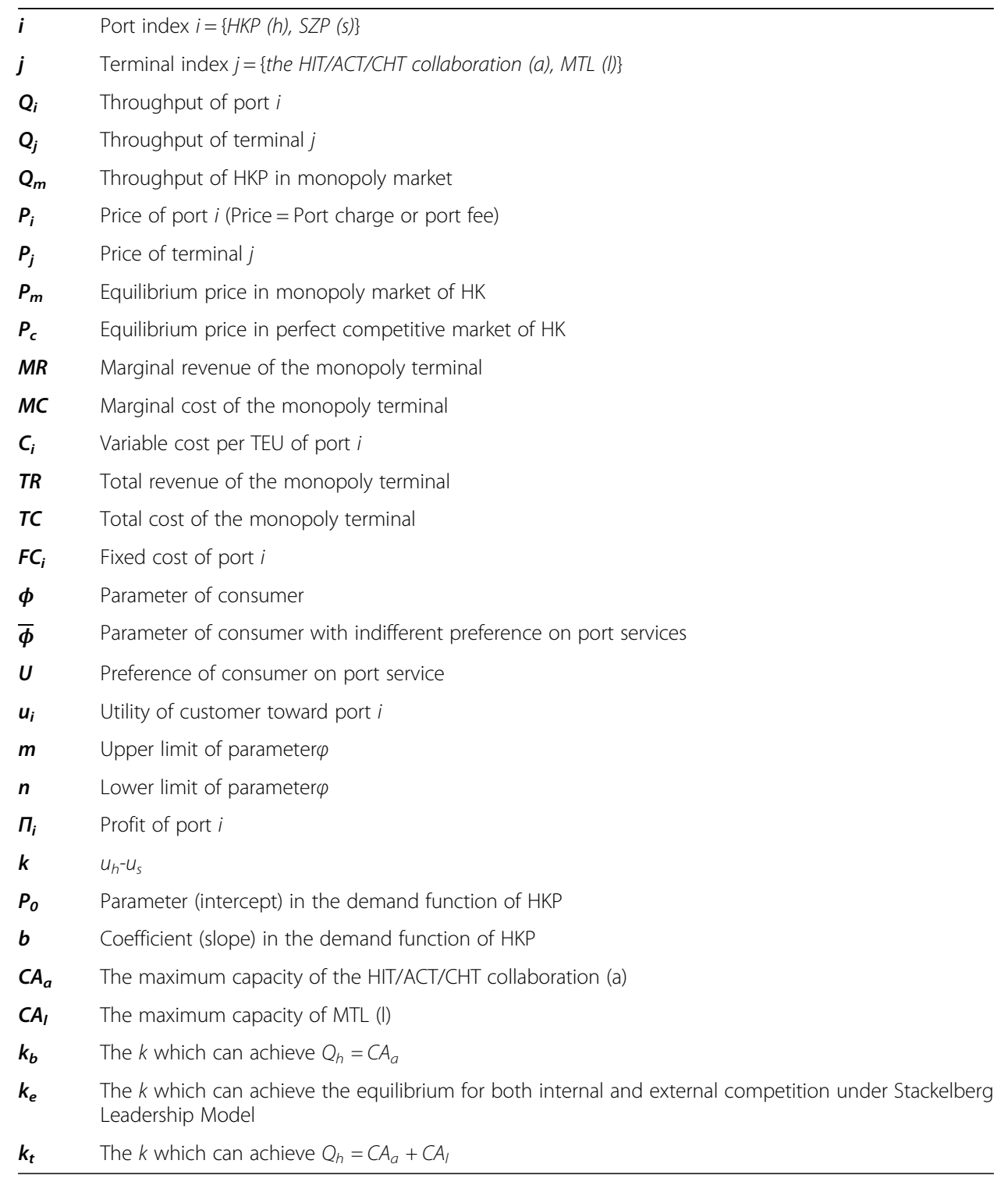

\section{External competition between HKP and SZP}

According to Cournot price competition model, each port who provides heterogeneous services regards the price of its competitor as an established price and changes its price in the same direction with its competitor in order to maximise its profits.

As the two ports provide heterogeneous services, they have different demand functions. Therefore, we need to firstly embody the heterogeneity in the demand 
function. In this study, utility function of port consumers is applied to extract the demand functions of HKP and SZP.

The consumers are denoted with the parameter $\phi$ and $\phi \in[n, m]$, where $0<n<m$, which is uniformly distributed with density equal to 1 . Then preference $U$ of consumer $\phi$ is described by the expected utility function $U_{i}\left(\phi, P_{i}\right)=\phi u_{i}-P_{i}$. Let $\bar{\phi}$ indicates the consumers with indifferent preference on port services. By solving $U_{h}\left(\phi, P_{h}\right)=U_{s}\left(\phi, P_{s}\right)$. We can obtain the $\bar{\phi}$ as:

$$
\bar{\phi}=\frac{P_{h}-P_{s}}{u_{h}-u_{s}}
$$

Now we assume the demand functions of HKP and SZP as:

$$
\begin{gathered}
Q_{h}=m-\bar{\phi}=m-\frac{P_{h}-P_{s}}{u_{h}-u_{s}} \\
Q_{s}=\bar{\phi}-n=\frac{P_{h}-P_{s}}{u_{h}-u_{s}}-n
\end{gathered}
$$

To simplify the calculation process, we assume $k=u_{h}-u_{s}$ which indicates the difference of consumer's utility toward the services provided by HKP and SZP, then we have:

$$
\begin{aligned}
Q_{h} & =m-\frac{P_{h}-P_{s}}{k} \\
Q_{s} & =\frac{P_{h}-P_{s}}{k}-n
\end{aligned}
$$

With the demand functions, we can formulate the profits of HKP and SZP as:

$$
\begin{aligned}
& \prod_{h}=Q_{h} \times\left(P_{h}-C_{h}\right)-F C_{h} \\
& \prod_{s}=Q_{s} \times\left(P_{s}-C_{s}\right)-F C_{s}
\end{aligned}
$$

The profit of HKP can be further described as:

$$
\prod_{h}=m P_{h}-m C_{h}-F C_{h}+\frac{P_{h} P_{s}-P_{h}^{2}+P_{h} P_{h}-P_{s} C_{h}}{k}
$$

To maximise the profit of HKP, we take the partial derivative $P_{h}$ for $(8)$ and it should be equal to 0 :

$$
\frac{\partial \prod_{h}\left(P_{h}, P_{s}\right)}{\partial P_{h}}=m+\frac{P_{s}+C_{h}-2 P_{h}}{k}=0
$$

Then the optimal (profit-max) price function of HKP under inter-port competition should be:

$$
P_{h}=\frac{m k+P_{s}+C_{h}}{2}
$$

Substitute it into demand function, we can find the optimal throughput function for HKP is: 


$$
Q_{h}=m-\frac{m k-P_{s}+C_{h}}{2 k}
$$

Similarly, we can obtain the optimal price function for SZP, which is:

$$
P_{s}=\frac{P_{h}+C_{s}-n k}{2}
$$

Then the optimal throughput function for SZP is:

$$
Q_{s}=\frac{P_{h-} C_{s}+n k}{2 k}-n
$$

By solving the eq. (10) and (12) together, we can obtain the optimal prices for HKP and SZP respectively, which are also the equilibrium prices under inter-port competition:

$$
\begin{aligned}
& P_{h}=\frac{(2 m-n) k+2 C_{h}+C_{s}}{3} \\
& P_{s}=\frac{(m-2 n) k+C_{h}+2 C_{s}}{3}
\end{aligned}
$$

Equation (14) indicates a positive correlation between $P_{h}$ and $k$. It means when the difference of customer utility towards HKP and SZP narrows, HKP has to reduce its price to improve the attractiveness to consumers.

Substitute $P_{h}$ and $P_{s}$ into (4) and (5), we can also obtain the equilibrium throughput for HKP and SZP as:

$$
\begin{aligned}
Q_{h} & =\frac{(2 m-n) k+C_{s}-C_{h}}{3 k} \\
Q_{s} & =\frac{(m-2 n) k+C_{h}-C_{s}}{3 k}
\end{aligned}
$$

\section{The impact of $\mathbf{k}$ on the equilibrium for external and internal competition}

As discussed, $k$ denotes the difference of consumers' utility towards the services provided by HKP and SZP, which is the level of heterogeneity. As shown in eq. (16), when the level of heterogeneity between HKP and SZP is large, the total throughput $Q_{h}$ of HKP will be large. When $Q_{h}$ is large, the container terminal operators in HKP may compete in terms of price since they provide homogenous services. Thus, we assume case 1 as:

\section{Case 1: Price competition (Edgeworth model)}

Edgeworth model is applicable when at a certain price level, the throughput of a firm cannot meet the whole market demand, that is, $Q_{h}>C A_{a}$ (The maximum capacity of the HIT/ACT/CHT collaboration), because MTL is highly unlikely to be able to satisfy the demand as it has less than half of the capacity as compared with the HIT/ACT/ CHT collaboration. This is persistent with practice.

In recent years, the service quality of SZP has been improving, and the trade freedom and customs clearance are more efficient, that the difference in the services provided by HKP (more efficient port services with higher price) and SZP (relatively less efficient port services with lower price) is less significant. This means that the level of 
heterogeneity $k$ between HKP and SZP is decreasing and HKP is losing its competitiveness and market share (throughput) in external competition (Luo et al. 2012). Based on the eq. (16), the total throughput of HKP $\left(Q_{h}\right)$ will decline simultaneously with the decreasing heterogeneity $(k)$. As discussed in section 3 , when $Q_{h}$ decreases to a certain level, the HIT/ACT/CHT collaboration and MTL can only compete by throughput level, because price competition is not a sustainable strategy for Hong Kong terminal operators, then we assume case 2 as:

\section{Case 2: capacity competition (Stackelberg leadership model)}

When $Q_{h}<C A_{a}$ we assume the HIT/ACT/CHT collaboration and MTL compete in term of capacity. Consider that the market share of the HIT/ACT/CHT collaboration is much larger than that of MTL at the ratio roughly at 16:7, where the capacity of MTL only accounts for less than $1 / 3$ of the total capacity of HKP, we can assume a leader-follower relationship between the HIT/ACT/CHT collaboration and MTL and Stackelberg Leadership model is applicable for the analysis of intra-port competition of HKP.

To sum up, when $k$ decreases, the intra-port competition of HKP will transform from price competition to capacity competition, where $k$ is determined by the inter-port competition of HKP and SZP. The impact of $k$ on the intra-port competitive equilibrium of HKP is shown in Fig. 3.

\section{Internal competition between MTL and the HIT/ACT/CHT collaboration}

In this section, we explore the intra-port competitive equilibrium of HKP of case 1 and case 2 scenarios, respectively.

\section{Case 1: Price competition (Edgeworth model)}

When $Q_{h}>C A_{a}$, according to Edgeworth model, there is no stable equilibrium price in the market and the market price will fluctuate between the monopoly market price and the perfect competitive market price. Therefore, we calculate the monopoly market price $P_{m}$ (upper limit) and the perfect competitive market price $P_{c}$ (lower limit). As the HIT/ACT/CHT collaboration and MTL produce homogeneous products, we assume that all terminals in HKP have the same cost function and cost structure.

Firstly, we assume the market demand curve of HKP is linear as:

$$
P=P_{0}-b Q
$$

In a monopoly market, with only one container terminal operator being the sole supplier for the whole market, the market demand curve is the operator's demand curve. To maximise its profit, the marginal revenue $(M R)$ of this operator must be

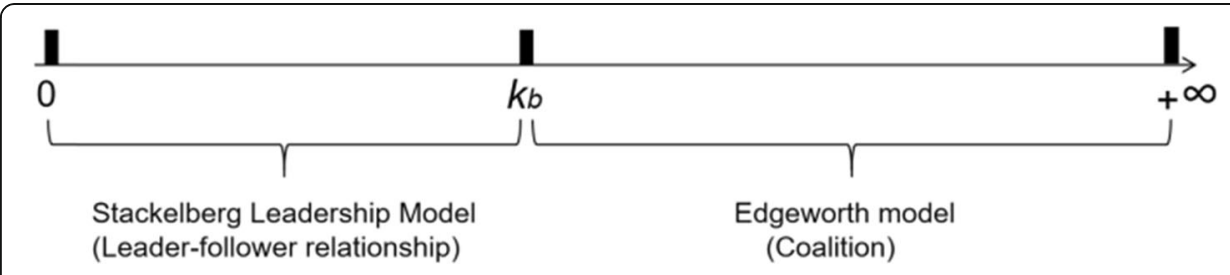

Fig. 3 The impact of $k$ on intra-port competition model. Note: $k_{b}$ denotes the $k$ achieving $Q_{h}=C A_{a}$ 
equal to its marginal cost $(M C) . M R$ and $M C$ are the derivatives of total revenue (TR) and total cost $(T C)$ respectively:

The $M R$ can be calculated as:

$$
M R=(T R)^{\prime}=\left(P_{0} Q-b Q^{2}\right)^{\prime}=P_{0}-2 b Q
$$

The $M C$ can be calculated as:

$$
M C=(T C)^{\prime}=\left(F C_{h}+C_{h} Q\right)^{\prime}=C_{h}
$$

We can obtain the throughput level in the monopoly market with eq. (19) and (20):

$$
Q_{m}=\frac{P_{0}-C_{h}}{2 b}
$$

Then the monopoly price of HKP is:

$$
P_{m}=P_{0}-b \times \frac{P_{0}-C_{h}}{2 b}=\frac{P_{0}+C_{h}}{2}
$$

While in a perfect competitive market, the market price $P_{c}$ must be equal to marginal cost $(M C)$, e.g. $P_{c}=C_{h}$.

Under case 1 , there is no equilibrium, alternatively, the equilibrium price $P_{h}$ fluctuates between $P_{m}$ and $P_{c}$, that is,. $C_{h}<P_{h}<\frac{P_{0}+C_{h}}{2}$.

\section{Case 2: capacity competition (Stackelberg leadership model)}

When $Q_{h}<C A_{a}$, according to Stackelberg Leadership model, the leader knows before the event that the follower observes its action and the follower cannot perform a nonStackelberg follower action in future. In HKP, the leader (the HIT/ACT/CHT collaboration) makes decision first and the follower (MTL) follows. If the HIT/ACT/CHT collaboration adjusts its supply (cargo type, container throughput level, etc.), the market price (e.g. cargo and container handling price, berthing charges, shipping price) will change, which in turn prompt MTL to change its respective throughput to maintain profit maximisation (Von Stackelberg 1934). In this case, individual terminal operators can make decisions on throughput expansion to achieve economies of scale and thus reduce their production costs, investing in service efficiency improvement and attracting more customers.

Since the demand function of HKP is linear, the profit of the follower (MTL), $\Pi_{l}$, is given as:

$$
\prod_{l}=\left(P-C_{h}\right) \times Q_{l}-F C_{h}
$$

It can be further described as:

$$
\prod_{l}=P_{0} Q_{l}-b Q_{l}^{2}-b Q_{a} Q_{l}-C_{h} Q_{l}-F C_{h}
$$

To maximise the profit of MTL, we take the partial derivative $Q_{l}$ and it should be equal to 0 :

$$
\left(\prod_{l}\right)^{\prime}=P_{0}-2 b Q_{l}-b Q_{a}-C_{h}=0
$$

The reaction function of the follower, MTL, is: 


$$
Q_{l}=\frac{P_{0}-b Q_{a}-C_{h}}{2 b}
$$

Then, the profit of the leader (the HIT/ACT/CHT collaboration), $\Pi_{a}$, can be described as:

$$
\prod_{a}=\frac{P_{0} Q_{a}}{2}-\frac{b Q_{a}^{2}}{2}-\frac{C_{h} Q_{a}}{2}-F C_{h}
$$

To maximise the profit of the HIT/ACT/CHT collaboration, we take the partial derivative $Q_{a}$ and it should be equal to 0:

$$
\left(\prod a\right)^{\prime}=\frac{P_{0}}{2}-b Q_{a}-\frac{C_{h}}{2}=0
$$

The optimal throughput of the leader, the HIT/ACT/CHT collaboration, is:

$$
Q_{a}=\frac{P_{0}-C_{h}}{2 b}
$$

The optimal throughput of the follower, MTL, is:

$$
Q_{l}=\frac{P_{0}-C_{h}}{4 b}
$$

Based on Stackelberg Leadership model, for intra-port competition, the throughput level of HKP is a constant value as follows:

$$
Q_{h}^{\prime}=Q_{a}+Q_{l}=\frac{3 P_{0}-3 C_{h}}{4 b}
$$

Therefore, substituting $Q_{h}$ ' into the demand function of HKP, the internal equilibrium price $P_{h}$ ' can be obtained:

$$
P_{h}^{\prime}=\frac{P_{0}+3 C_{h}}{4}
$$

\section{Interconnection between internal competition and external competition}

To better understand the interconnection between intra-port and inter-port competition, the last step is to analyse both competitions simultaneously. As shown in Fig. 3, $Q_{h}=C A_{a}$ is the boundary which determines the structure of intra-port competition. By inputting $Q_{h}=C A_{a}$ into eq. (16), $k_{b}$ (the $k$ which can achieve $Q_{h}=C A_{a}$ ) can be obtained:

$$
k_{b}=\frac{C_{h}-C_{s}}{2 m-n-3 C A_{a}}
$$

If $0<k<k_{b}$, the leader-follower relationship exists between the HIT/ACT/CHT collaboration and MTL. According to eq. (31), the internal equilibrium throughput of HKP is a constant value $\left(Q_{h}{ }^{\prime}\right)$, which is not necessary to be the equilibrium throughput determined by inter-port competition $\left(Q_{h}\right)$. Thus, there is only one level of heterogeneity $\left(k_{e}\right)$ falling within the range $0<k<k_{b}$ can achieve the overall equilibrium for both intra-port and inter-port competition. We can solve this $k_{e}$ by equating the internal equilibrium price $\left(P_{h}{ }^{\prime}\right)$ and the external equilibrium price $\left(P_{h}\right)$ : 


$$
k_{e}=\frac{C_{h}+3 P_{0}-4 C_{s}}{8 m-4 n}
$$

The overall equilibrium for both intra-port and inter-port competition can only be achieved when $k=k_{e}$ within the range $0<k<k_{b}$. However, the level of heterogeneity $(k)$ is not determined by the container terminal operators in HKP but multiple factors, including but not limited to government policy, efficiency of customs clearance, service quality, etc. Since container terminal operators cannot move $k$ to $k_{e}$ in short term, the overall equilibrium does not exist at the time that $k \neq k_{e}$.

If $k_{b}<k<+\infty$, there is no stable internal equilibrium price in the market and the market price will fluctuate between the monopoly market price and the perfect competitive market price. According to Edgeworth model, when MTL increases its price, the HIT/ACT/CHT collaboration will also increase price to compete with MTL. Then the total throughput of HKP will decrease and vice versa. Such the decrease and increase of HKP throughput will trigger the response from SZP, only when the optimal throughput of HKP is equal to the external equilibrium throughput level $Q_{h}$, can the competitive equilibrium for both inter-port competition and intra-port competition be achieved. This equilibrium can be represented by eq. (35):

$$
Q_{h}=\frac{(2 m-n) k+C_{s}-C_{h}}{3 k}=Q_{a}+Q_{l}
$$

From eq. (35), there will be two cases when the equilibrium can be reached:

Case (i). The HIT/ACT/CHT collaboration and MTL set different prices to make the sum of their throughput reach $Q_{h}$, and Case (ii), they set an uniform price at $P_{a}=P_{l}=$ $P_{h}$ to reach $Q_{h}$.

In reality, Case (i) is less likely to be achieved because of the non-transparent port fee (price) mechanism and the independent operation strategy in HKP. First of all, there are different price levels for categorised consumers, e.g. special rate for consumers purchasing in bulk. It is hard for them to reflect the market change in short time. Also, due to their independent operation strategies, it is difficult for the HIT/ACT/CHT collaboration and MTL to collaborate and cooperate in the sense of better allocation of resources to provide more efficient services. Considering the rapid increase in the service efficiency of SZP, the heterogeneity between HKP and SZP is decreasing recently and thus widening the gap in throughput level between HKP and SZP. The infeasibility of case (i) is proved by the historical data of the throughput levels of HKP and SZP. Before 2019, the HIT/ACT/CHT collaboration and MTL adapted independent pricing strategy and operation strategy. However, below table indicates that these strategies are not efficient to protect HKP's position against SZP, because the throughput level of HKP is decreasing continuously and the gap in throughput between HKP and SZP is becoming wider and wider. This data may prove that it is difficult for HKP to achieve the equilibrium in case (i) Table 2.

Compared to Case (i), Case (ii) is more feasible that a coalition can be formed. It can at least achieve two advantages. First, easy to response to the external competition through setting an uniform price, in order to maximise the overall throughput. Second, forming a coalition may allow both the HIT/ACT/CHT collaboration and MTL to reduce cost through reducing surplus operation, sharing resource, etc. This also to some content, relieves the pressure from the decrease of heterogeneity between HKP 
Table 2 Ranking of Container Ports of World

\begin{tabular}{llllllll}
\hline OOO0 TEUS & 2012 & 2013 & 2014 & 2015 & 2016 & 2017 & 2018 \\
\hline HKP & 23,117 & 22,352 & 22,226 & 20,073 & 19,813 & 20,770 & 19,596 \\
SZP & 22,941 & 23,278 & 24,037 & 24,205 & 23,979 & 25,209 & 25,736 \\
\hline
\end{tabular}

Source: Hong Kong Marine Department (HKMD) 2018

and SZP. Based on our model, the best strategy for the container terminal operators in HKP to achieve profit maximisation is to collaborate and cooperate in the sense of better allocation of resources to provide more efficient port services and reduce the production cost. Wong et al. (2018) propose a collaboration model for Hong Kong terminal operators to collaborate with each other to share their facilities, including berths, cranes, and yards. With this collaboration, vessels with high transshipment connections are allowed to berth within the same terminal to avoid unnecessary ITT. On 8th January, 2019, Hong Kong International Terminals Limited, Modern Terminals Limited, COSCO-HIT Terminals (Hong Kong) Limited, and Asia Container Terminals Limited announced the formation of the "Hong Kong Seaport Alliance", a joint agreement designed to deliver more efficient services offering to carriers. In fact, the "Hong Kong Seaport Alliance" was approved and gradually implemented from 1st April (Hutchison Ports HIT 2019). Since this paper mainly focuses on qualitative analysis, the strategy of forming coalition applied by the terminals under HKP is expected to validate our model.

However, the accurate upper level of $k$ is not $+\infty$, because both the monopoly price in Edgeworth model and the extreme case that the maximum capacity cannot satisfy $Q_{h}$ will affect it:

On the one hand, according to Edgeworth model, the market equilibrium price of HKP $\left(P_{h}\right)$ is limited to a range between the upper limit (monopoly price) and lower limit (perfect competitive market price), i.e. $C_{h}<P_{h}<\frac{P_{0}+C_{h}}{2}$.

We can obtain the range of $k$ if the $P_{h}$ in Edgeworth model is substituted by eq. (14):

$$
\frac{C_{h}-C_{s}}{2 m-n}<k<\frac{1}{2} \frac{3 P_{0}-2 C_{s}-C_{h}}{2 m-n}
$$

As mentioned above, the applicable range of Edgeworth model is:

$$
k_{b}<k<+\infty
$$

When Edgeworth model is applied, the range of $k$ should also meet the range set by eq. (36). Thus, we consider the constraints of eq. (36) and (37) simultaneously and derive the range of $k$ for the application of Edgeworth model as:

$$
k_{b}<k<\frac{1}{2} \frac{3 P_{0}-2 C_{s}-C_{h}}{2 m-n}
$$

On the other hand, if the equilibrium throughput level $\left(Q_{h}\right)$, which is determined by external competition, outnumbers the maximum capacity of HKP, the equilibrium will not be achieved. In the long term, HKP will lose its position. Since $Q_{h}$ is only determined by heterogeneity $k$ and they are positively correlated, the $k\left(k_{t}\right)$ which can produce the highest $Q_{h}$, where $Q_{h}=C A_{a}+C A_{l}$, is supposed to be the other upper limit of $k$. 
From equation $Q_{h}=C A_{a}+C A_{l}$, a new upper level of $k\left(k_{t}\right)$ can be calculated and a new applicable range of $k$ is derived as eq. (39):

$$
k_{b}<k<k_{t}=\frac{C_{h}-C_{s}}{2 m-n-3\left(C A_{a}+C A_{l}\right)}
$$

Comparing the two upper levels of $k$ in eqs. (38) and (39), we find that in Edgeworth model, the applicable range of $k$, where the equilibrium exists, is determined by the maximum capacity of HKP $\left(C A_{a}+C A_{l}\right)$. The results of characterization (case 1 and case 2) are as follows:

Case 1:

$$
\mathrm{CA}_{\mathrm{a}}+\mathrm{CA}_{\mathrm{l}}>\frac{C_{h}(6 m-3 n)+P_{0}(3 n-6 m)}{\left(3 C_{h}+6 C_{s}-9 P_{0}\right)}
$$

The applicable range of $k$ :

$$
k_{b}<k<\frac{1}{2} \frac{3 P_{0}-2 C_{s}-C_{h}}{2 m-n}
$$

Case 2:

$$
\mathrm{CA}_{\mathrm{a}}+\mathrm{CA}_{\mathrm{l}}<\frac{C_{h}(6 m-3 n)+P_{0}(3 n-6 m)}{\left(3 C_{h}+6 C_{s}-9 P_{0}\right)}
$$

The applicable range of $k$ :

$$
k_{b}<k<k_{t}=\frac{C_{h}-C_{s}}{2 m-n-3\left(C A_{a}+C A_{l}\right)}
$$

As $k$ represents the difference of consumers' utility towards the services provided by HKP and SZP, when $k=+\infty$, the nature of services provided by HKP and SZP is completely different and different needs of consumers can be fulfilled. In this way, competition will not exist. In contrast, when $k=0$, the services of HKP and SZP are homogenous and it becomes a Bertrand game. Under this circumstance, all consumers will choose the port with lower price, i.e. SZP in our case.

\section{Conclusion and implication}

In this study, we build a framework to analyse the competitive equilibrium of inter-port competition between HKP and SZP, as well as the intra-port competition among container terminal operators in HKP simultaneously. By employing the Cournot price competition model, Edgeworth model, and Stackelberg Leadership model, we have better understanding in the inter-port competition between HKP and SZP, the intra-port competition in HKP, and the relationship between inter-port and intra-port competition. We apply Cournot price competition model to study the inter-port competition between HKP and SZP, highlighting the importance of heterogeneity in the services provided by these two ports. With a higher level of heterogeneity in services, the demand for HKP will remain high and vice versa. By incorporating different demand functions associated with the level of heterogeneity, Edgeworth model and Stackelberg Leadership model are employed to study the intra-port competition of container terminal operators in HKP. Our study builds upon previous literature from two perspectives: (i). we focus on the impact of heterogeneity of services on the competitive 
equilibrium; (ii). we consider the interaction between the intra-port and inter-port competition.

We found that (i). the external competition will determine the internal competition in terms of the equilibrium throughput of HKP; (ii). the heterogeneity level between HKP and SZP (external competition) may lead to different internal competitive equilibriums; (iii). for the terminal operators under HKP, forming a port coalition can, in the maximum extent, help them mitigate the negative impact from the decreasing heterogeneity. The operators in HKP should collaborate and cooperate to improve the service efficiency and reduce the cost to compete with SZP. On the one hand, if the efficiency of HKP increases, the heterogeneity $k$ between HKP and SZP will increase as well. Therefore, according to eq. (16), the demand for HKP $\left(Q_{h}\right)$ will increase; On the other hand, when the operating cost is reduced by HKP, according to eq. (16), $Q_{h}$ will also increase.

The academic contribution of this study is to discuss the mechanism for both internal and external port competitions and their relationship, and to provide the strategies for the terminal operators under HKP to protect their competitive positions. In this way, the establishment of the 'Hong Kong Seaport Alliance' can prove the feasibility and accuracy of our model.

To maintain the competitiveness of HKP while facing the inter-port competition with SZP, the HKSAR government plays a vital role. As indicated by Tongzon (2009), port infrastructure is one of the crucial factors to attract consumers. In such sense, policy makers should re-evaluate the possibility of building Terminal 10 at Tsing Yi Island to increase container terminal capacity. Alongside with port infrastructure, the transportation network connecting to hinterland and multimodal transport is also important. The government should also improve the efficiency of customs clearance and the quality of infrastructure. The operators cannot increase the terminal capacity, yet they can adopt efficient management of berth allocation to accommodate more consumers, and maintain a competitive terminal handling fee.

This paper can be further extended from the following aspects. Firstly, the advantages from collaboration can be reflected by incorporating the factor of increasing returns to scale into the profit functions of container terminal operators. Secondly, multiple container terminal operators operate in SZP, including HIT who also operates terminals in HKP, a more complex competitive structure can be taken into consideration in the future. Finally, an empirical study is necessary to be conducted to validate our model.

\section{Abbreviations}

ACT: Asia Container Terminals Limited; CHT: COSCO-HIT Terminals (Hong Kong) Limited; DPI: Goodman DP World Hong Kong Limited; HIT: Hong Kong International Terminals Limited; HKP: The Port of Hong Kong; HKSAR: Hong Kong Special Administrative Region of the People's Republic of China; MTL: Modern Terminals Limited; SZP: The Port of Shenzhen

Acknowledgements

Not applicable. 


\section{Funding}

This research did not receive any specific grant from funding agencies in the public, commercial, or not-for-profit sectors.

\section{Availability of data and materials}

Not applicable.

\section{Competing interests}

The authors declare that they have no competing interests.

\section{Author details}

${ }^{1}$ Faculty of Engineering, University of Hong Kong, Hong Kong SAR, China. ${ }^{2}$ Shipping Research Centre, The Hong Kong

Polytechnic University, Hong Kong SAR, China.

Received: 2 September 2019 Accepted: 6 March 2020

Published online: 31 March 2020

\section{References}

Anderson CM, Park YA, Chang YT, Yang CH, Lee TW, Luo M (2008) A game-theoretic analysis of competition among container port hubs: the case of Busan and Shanghai. Marit Policy Manag 35(1):5-26

Cournot A (1838) Researches into the principles of the theory of wealth. Macmillan \& Co., Ltd., London

Cullinane K, Teng Y, Wang TF (2005) Port competition between shanghai and Ningbo. Marit Policy Manag 32(4):331-346

Davidson C, Deneckere R (1986) Long-run competition in capacity, short-run competition in price, and the Cournot model. RAND J Econ:404-415

De Borger B, Proost S, Van Dender K (2008) Private port pricing and public investment in port and hinterland capacity. J Transport Econ Policy 42:527-561

Do TMH, Park GK, Choi K, Kang K, Baik O (2015) Application of game theory and uncertainty theory in port competition between Hong Kong port and Shenzhen port. Int J e-Navigation Maritime Econ 2:12-23

Edgeworth FY (1897) The Pure Theory of Monopoly

Hong Kong Marine Department (HKMD). (2018). Ranking of Container Ports of the World. Retrieved from: https://www. mardep.gov.hk/en/publication/pdf/portstat_2_y_b5.pdf

Hong Kong Container Terminal Operators Association (2018). Kwai Tsing Container Port/Port Facilities. Retrieved from the world wide web on 15 March 2018 from. http://www.hkctoa.com/facilities

Hutchison Port Holdings Trust (2017). Unaudited Financial Statement Announcement for the third quarter and nine months ended 30 september 2017. Retrieved from the world wide web on 4 April 2019 from: http://www.hphtrust.com/ newsroom/20171030_172336_NS8U_J8IGUEV0005PGF19

Hutchison Ports HIT (2016). Signing of Co-management Agreement Between Hutchison Port Holdings Trust and COSCO SHIPPING Ports Limited. Retrieved from the world wide web on 4 April 2019 from: https://goo.gl/jtfUWMlshii

Hutchison Ports HIT (2019). Container Terminal Operators to Form the "Hong Kong Seaport Alliance" Enhancing the Competitiveness of the Port of Hong Kong. Retrieved from the world wide web on 23 April 2019 from: https://www.hit. com.hk/en/Media-Centre/Press-Release/Hong-Kong-Seaport-Alliance.html

Ishii M, Lee PTW, Tezuka K, Chang YT (2013) A game theoretical analysis of port competition. Transportation Research Part E: Logistics and Transportation Review 49(1):92-106

Ivaldi M, Vibes C (2005) Intermodal and intramodal competition in passenger rail transport

Kaselimi EN, Notteboom TE, De Borger B (2011) A game theoretical approach to competition between multi-user terminals: the impact of dedicated terminals. Marit Policy Manag 38(4):395-414

Lee D, Lim S, Choi K (2017) Port privatization under Cournot vs. Bertrand competition: a third-market approach. Marit Policy Manag 44(6):761-778

Luo M, Liu L, Gao F (2012) Post-entry container port capacity expansion. Transp Res B Methodol 46(1):120-138

Ma HL, Wong CWH, Leung LC, Chung SH (2019). Facility sharing in business-to-business model: a real case study for container terminal operators in Hong Kong port. Int J Prod Econ. https://doi.org/10.1016/j.jpe.2019.09.004

Mongelluzzo B (2015). FMC gives green light to SeattleTacoma port alliance. Retrieved from the world wide web on 4 April 2019 from: http://worldmaritimenews.com/archives/167313/fmc-gives-green-light-to-northwest-seaport-alliance/

Park GK, Han X, Lu DQ (2010) Analysis of port competition using game theory. In: SCIS \& ISIS SCIS \& ISIS 2010, pp 805-808 Japan Society for Fuzzy Theory and Intelligent Informatics

Research in transportation economics (2018) Research in transportation economics. Res Transp Econ

Saeed N, Larsen OI (2010) An application of cooperative game among container terminals of one port. Eur J Oper Res 203(2): 393-403

Song D-W (2002) Regional container port competition and co-operation: the case of Hong Kong and South China. J Transport Geography 10(2):99-110

Song D-W (2003) Port co-opetition in concept and practice. Maritime Policy \& Management 30(1):29-44.

Tongzon J (2009) Port choice and freight forwarders. Transportation Research Part E: Logistics and Transportation Review 45(1):186-195

Veldman ASJ, Bückmann EH (2003) A model on container port competition: an application for the west European container hub-ports. Maritime Econ Logistics 5(1):3-22

Von Stackelberg H (1934). Marktform und gleichgewicht. Wien: Springer

Wong CW, HL, H, Leung LC (2018). Collaboration at the Hong Kong port-benefits from facility sharing. Policy Research Institute of Global Supply Chain. Hong Kong: Hang Seng Management College

\section{Publisher's Note}

Springer Nature remains neutral with regard to jurisdictional claims in published maps and institutional affiliations. 